\title{
TINGKAT KENYAMANAN DI HUTAN KOTA PATRIOT BINA BANGSA KOTA BEKASI
}

\section{(THE COMFORT LEVEL OF PATRIOT BINA BANGSA URBAN FOREST IN BEKASI CITY)}

\author{
Audy Evert, Slamet Budi Yuwono, dan Duryat \\ Jurusan Kehutanan, Fakultas Pertanian, Universitas Lampung \\ Jl. Soemantri Brojonegoro No 1 Bandar Lampung \\ Email : evert.audy@gmail.com \\ Phone : 08989863595
}

\begin{abstract}
ABSTRAK
Perkembangan wilayah perkotaan yang sangat cepat dapat menimbulkan permasalahan lingkungan seperti meningkatnya suhu udara dan penurunan kualitas lingkungan. Keberadaan Ruang terbuka hijau (RTH) diperlukan untuk dapat mengatasi permasalahan lingkungan tersebut. Tujuan penelitian ini adalah mengetahui karakteristik pohon penyusun Hutan Kota Patriot Bina Bangsa, meliputi jenis, kerapatan, luas tutupan tajuk dan mengetahui indeks kenyamanan Hutan Kota Patriot Bina Bangsa serta mengetahui persepsi pengunjung terhadap tingkat kenyamanan fasilitas Hutan Kota Patriot Bina Bangsa. Metode yang digunakan pada penelitian ini adalah analisis vegetasi dengan melakukan sensus semua pohon yang ada dalam kawasan. Temperature Humidity Indexs (THI) digunakan untuk mengetahui tingkat kenyamanan. Metode wawancara dengan random sampling sebanyak 100 responden digunakan untuk mengetahui persepsi pengunjung.Hasil penelitian menunjukkan bahwa karakteristik vegetasi penyusun Hutan Kota Patriot Bina Bangsa sangat berpengaruh pada suhu dan kelembaban. Kerapatan yang tinggi dapat menurunkan suhu dan meningkatkan kelembaban. Kelas tajuk rapat memiliki suhu udara sebesar $27,6^{\circ} \mathrm{C}$ dan kelembaban udara sebesar $80,1 \%$. Kelas tajuk sedang memiliki suhu udara sebesar $29,1^{\circ} \mathrm{C}$ dan kelembaban udara sebesar $73,2 \%$. Kelas tajuk jarang memiliki suhu udara sebesar $30,1^{\circ} \mathrm{C}$ dan kelembaban udara sebesar 70,5\%. Berdasarkan indek suhu dan kelembaban (THI) Hutan Kota Patriot Bina Bangsa tergolong tidak nyaman, dengan nilai $>26$. Sebagian besar pengunjung $(77,82 \%)$ berpendapat fasilitas yang terdapat di Hutan Kota Patriot Bina Bangsa tergolong baik
\end{abstract}

Kata kunci :Hutan Kota Patriot Bina Bangsa, kenyamanan hutan kota, kota

\section{ABSTRACT}

The development of urban area was accured quickly and lead to many environmental problems such as the rising of temperatures and decreasing of environmental quality. Green open space (RTH) was needed to overcome those problems. The objectives of the research were to figure out the characteristics of vegetation in Patriot Bina Bangsa Urban Forest (including the species, density, broad canopy coverage), to figure out comfort index of Patriot Bina Bangsa Urban Forest and to find out the visitor's perception about comforts value of facilities. The analysis of vegetation was employed as the method of data collection sensus method was used as the sampling method, and temperature humidity index (THI) was used to determine the comfort level. Interview techniques with random sampling method was used to determine the visitors perception. The result showed that the vegetation characteristics of Patriot Bina Bangsa Urban Forest took effects to temperature and humidity. High density of tree could decrease the air temperature and increase the humidity, 
where dense canopy class had air temperature at $27.6^{\circ} \mathrm{C}$ and humidity at $80.1 \%$; moderate canopy class had air temperature at $29.1{ }^{\circ} \mathrm{C}$ and humidity at $73.2 \%$; sparse canopy class had air temperature at $30.1^{\circ} \mathrm{C}$ and humidity at $70.5 \%$. Based on the temperature humidity index (THI), Patriot Bina Bangsa Urban Forest was categorized as uncomfortable, with THI values >26. Most of visitors (77.72\%) believed that the facilities wich exist in Patriot Bina Bangsa Urban Forest ware categorized good.

Key words :Patriot Bina Bangsa Urban Forest, urban forest comfort, city

\section{PENDAHULUAN}

Perkembangan kawasan perkotaan di Indonesia bergerak sangat cepat dan hal ini diindikasikan oleh semakin meningkatnya jumlah penduduk yang tinggal dan beraktivitas di wilayah perkotaan. Pertambahan jumlah penduduk yang tidak diiringi oleh peningkatan daya dukung lingkungan dapat mengakibatkan timbulnya masalah perkotaan seperti meningkatnya suhu udara dan penurunan kualitas lingkungan. Permasalahan kerusakan lingkungan hidup dapat diatasi dengan keberadaan Ruang Terbuka Hijau (RTH). Ruang terbuka hijau merupakan ruang alami yang menjadi bagian penting bagi suatu kota berkaitan dengan penanggulangan berbagai masalah perkotaan (Zoer'aini, 1995).

Keberadaan RTH sangat diperlukan bagi wilayah perkotaan. Adanya RTH diharapkan mampu menanggulangi permasalahan lingkungan perkotaan terutama dalam menetralisir dampak negatif yang disebabkan oleh aktivitas perkotaan. RTH melalui perannya sebagai pengatur iklim mikro dapat menurunkan suhu permukaan yang secara langsung berpengaruh terhadap sebaran suhu udara dan dapat meningkatkan kenyamanan hidup masyarakat (Ahmad, 2012).

Hutan Kota Patriot Bina Bangsa merupakan salah satu RTH di Kota Bekasi. Berdasarkan hasil pengukuran dengan menggunakan interpretasi citra Hutan Kota Patriot Bina Bangsa memiliki luas sebesar $6 \mathrm{Ha}$. Hutan kota ini tidak hanya dapat difungsikan sebagai kawasan resapan air tetapi juga dijadikan sebagai ruang aktivitas publik yang berbasis pelestarian kawasan hijau. Keberadaan hutan kota dapat menjadi suatu komponen penting dalam mempertahankan kenyamanan kota bagi penduduknya melalui fungsinya dalam menjaga iklim mikro kota (Hussein dkk, 2010).

Hutan kota dapat dijadikan sebagai ruang aktivitas publik. Ruang aktivitas publik yang baik harus nyaman karena nyamannya suatu RTH akan meningkatkan produktifitas orang didalamnya (Rahmawati, 2014). Aspek kenyamanan yang akan dikaji pada penelitian ini adalah suhu udara, kelembaban udara dan fasilitas.

Untuk mengetahui efektivitas fungsi hutan kota dalam memberikan kenyamanan terhadap masyarakat, maka tingkat kenyamanan Hutan Kota Patriot Bina Bangsa perlu untuk dikaji. Tujuan penelitian ini adalah mengetahui karakteristik pohon penyusun Hutan Kota Patriot Bina Bangsa, meliputi jenis, kerapatan, luas tutupan tajuk dan mengetahui indeks kenyamanan berdasarkan suhu dan kelembaban (THI) serta mengetahui persepsi pengunjung terhadap tingkat kenyamanan fasilitas hutan kota.

\section{METODE PENELITIAN}

\section{Waktu dan Lokasi Penelitian}

Penelitian dilakukan pada bulan Desember 2015 di Hutan Kota Patriot Bina Bangsa Kota Bekasi Jawa Baratyang dikelola oleh Badan Pengelola Lingkungan Hidup (BPLH) Kota Bekasi. Lokasi penelitian dapat dilihat pada (Gambar 1). Areal penelitian dibagi menjadi 
tiga kelas tutupan tajuk yaitu; tajuk rapat (tegakan mahoni), tajuk sedang (taman bermain), dan tajuk jarang (lintasan sepatu roda).

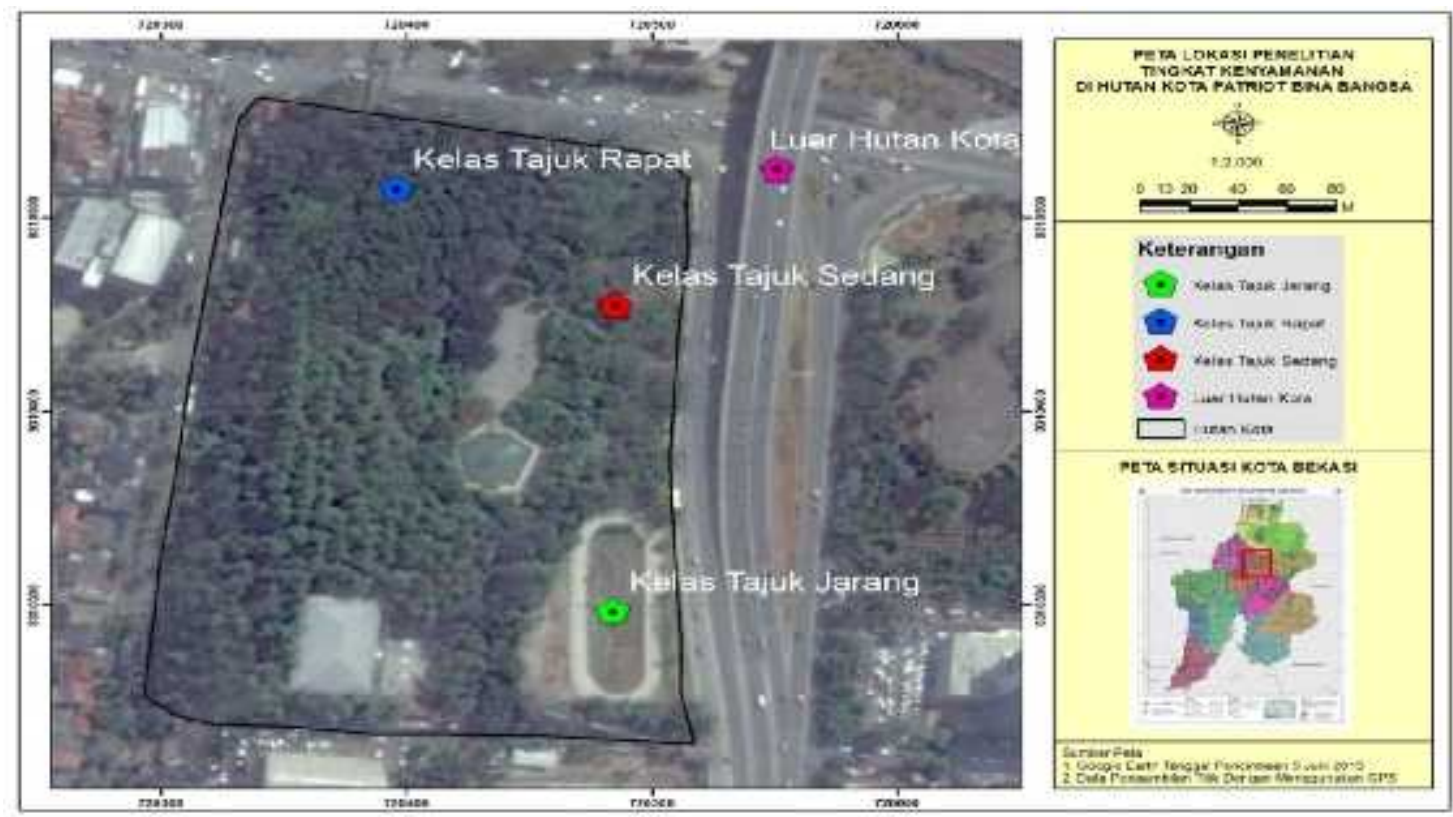

Gambar 1. Peta lokasi penelitian.

\section{Alat dan Bahan}

Alat-alat yang digunakan dalam penelitian ini adalah termometer digital, higrometer, pita diameter, christen hypsometer dan kuesioner. Bahan yang digunakan dalam penelitian ini adalah tegakan Hutan Kota Patriot Bina Bangsa.

\section{Metode Penelitian}

Karakteristik pohon penyusun Hutan Kota Patriot Bina Bangsa didapatkan dengan metode analisis vegetasi yaitu mensensus semua pohon yang berada di Hutan Kota Patriot Bina Bangsa. Pengukuran suhu dan kelembaban udara dilakukan sebanyak 7 kali dalam kurun waktu 14 hari, pada pagi hari pukul 07.00 - 08.00, siang hari pukul $12.00-13.00$ dan sore hari pada pukul 16.00 - 17.00dengan alasan pembagian kisaran radiasi matahari pada pagi hari, siang hari, dan sore hari (Tjasjono, 1999). Untuk mengetahui persepsi pengunjung terhadap tingkat kenyamanan hutan kota dilakukan menggunakan metode random sampling dengan caramewawancarai langsung dibantu dengan kuesioner. Berdasarkan rumus Arikunto (2011), jumlah responden yang diwawancarai sebanyak 100 responden.Tingkat kenyamanan didapatkan dari pengukuran nilai suhu dan kelembaban udara

\section{Analisis Data}

Analisis data untuk mengetahui nilai THI dilakukan dengan rumus sebagai berikut : $\mathrm{THI}=0,8 \mathrm{~T}+(\mathrm{RH} \times \mathrm{T}) /$ 500(Nieuwolt and Mc Gregor,1998).

Keterangan : $\mathrm{T}=$ suhu udara $; \mathrm{Rh}=$ kelembaban udara.

Suhu udara dan kelembaban udara diukur menggunakan hygrometer. Nieuwolt and Mc Gregor (1998), menyatakan bahwa kriteria tingkat kenyamanan digolongkan dalam tiga kriteria yaitu, nyaman dengan nilai THI 21 - 24, sedang dengan nilai 25 - 26 dan nilai THI $>26$ dinyatakan tidak nyaman. Hasil wawancara dengan responden akan ditabulasi dan dianalisis untuk mengetahui penilaian pengunjung terhadap kenyamanan Hutan Kota Patriot Bina Bangsa. 


\section{HASIL DAN PEMBAHASAN}

\section{Karakteristik Pohon Penyusun Hutan Kota Patriot Bina Bangsa}

\section{A. Kelas Tajuk Rapat}

Lokasi hutan kota yang tajuknya rapat di dominasi oleh pohon mahoni. Pohon lain yang ditemui pada lokasi ini adalah Biola cantik ( 3 individu) dan Gempol ( 2 individu). Total kerapatan pohon pada kelas tajuk rapat adalah 251,51 pohon/ha dan total luas tutupan tajuk adalah $16.925,14 \mathrm{~m}^{2} /$ ha (Tabel 1$)$.

Tabel 1. Kerapatan pohon dan luas tutupan tajuk di kelas tajuk rapat.

\begin{tabular}{lllrrr}
\hline No & Nama Jenis & \multicolumn{1}{c}{ Nama Ilmiah } & $\begin{array}{c}\text { Jumlah } \\
\text { Individu }\end{array}$ & $\begin{array}{c}\text { Kerapatan } \\
\text { (pohon/ha) }\end{array}$ & $\begin{array}{c}\text { Luas Tajuk } \\
\left(\mathbf{m}^{2} / \mathbf{h a}\right)\end{array}$ \\
\hline 1. & Mahoni & Swietenia macrophylla & 20 & 202,02 & $13.822,73$ \\
2. & Biola cantik & Ficus pandurata & 3 & 30,30 & 1.350 \\
3. & Gempol & Nauclea orientalis & 2 & 20,20 & $1.752,42$ \\
\hline & Total & & 25 & 252,51 & $16.925,14$ \\
\hline
\end{tabular}

Sumber : Data primer (2015)

Berdasarkan Tabel 1, diketahui bahwa terdapat 3 spesies pohon dengan jumlah 25 individu. Jenis pohon dikelas tutupan tajuk tapat didominasi oleh jenis pohon peneduh yaitu mahoni. Berdasarkan hasil wawancara dengan pengelola yaitu BPLHD Kota Bekasi, pohon mahoni sengaja dipilih untuk ditanam di hutan kota karena memiliki karakter tumbuh tajuk melebar, rapat dan rimbun, sehingga area yang terlindungi dari sinar matahari cukup luas. Selain itu, pohon mahoni memiliki jumlah daun yang banyak sehingga dapat mereduksi panas dengan baik. Adaptasi yang tinggi menyebabkan pohon ini mampu hidup di kondisi suhu yang panas dan kering.

Kualitas RTH berkaitan erat dengan kerapatan pohon bertajuk rindang yang menyusun vegetasinya.Semakin tinggi kerapatan pohon pada suatu wilayah maka kualitas RTH akan semakin baik (Laksmiwati, 2012).Hasil penelitan menunjukkan bahwa kerapatan pohon pada lokasi ini termasuk katagori baik yaitu 252,52 pohon/ha. Fandeli (1992) mengkelaskan kerapatan dalam 4 katagori yaitu katagori buruk dengan nilai 12-50, sedang dengan nilai 51100, cukup dengan nilai 101-200, dan baik dengan nilai $>201$.

\section{B. Kelas Tajuk Sedang}

Kelas tajuk sedang berada di bagian depan Hutan Kota Patriot Bina Bangsa. Kelas tajuk sedang merupakan lokasi taman bermain. Banyak fasilitas bermain anak yang berada di kelas tajuk sedang seperti ayunandan jungkat-jungkit. Total kerapatan pohon pada kelas tajuk sedang adalah 121,1 pohon/ha dan total luas tutupan tajuk pada lokasi ini adalah $8.065,85 \mathrm{~m}^{2} /$ ha (Tabel 2).

Tabel 2. Kerapatan pohon dan luas tutupan tajuk di kelas tajuk sedang.

\begin{tabular}{lllrrr}
\hline No & Nama Jenis & \multicolumn{1}{c}{ Nama Ilmiah } & $\begin{array}{c}\text { Jumlah } \\
\text { Individu }\end{array}$ & $\begin{array}{c}\text { Kerapatan } \\
\text { (pohon/ha) }\end{array}$ & $\begin{array}{c}\text { Luas Tajuk } \\
(\mathbf{m} \text { /ha) }\end{array}$ \\
\hline 1. & Mahoni & Swietenia macrophylla & 3 & 30,30 & $1.181,51$ \\
2. & Biola cantik & Ficus pandurata & 2 & 20,20 & $1.411,41$ \\
3. & Gempol & Nauclea orientalis & 2 & 20,20 & $1.242,82$ \\
4. & Flamboyan & Delonix regia & 3 & 30,30 & $2.927,99$ \\
5. & Tanjung & Mimousop elangi & 2 & 20,20 & $1.302,12$ \\
\hline & & Total & $\mathbf{1 2}$ & $\mathbf{1 2 1 , 1 0}$ & $\mathbf{8 . 0 6 5 , 8 5}$ \\
\hline
\end{tabular}

Sumber : Data primer(2015) 
Berdasarkan Tabel 2, diketahui bahwa terdapat 5 spesies pohon dengan jumlah 12 individu. Jenis pohon yang berada di kelas tajuk sedang yaitu flamboyan, mahoni, biola cantik, gempol dan tanjung. Pohon flamboyan memiliki bentuk tajuk pohon yang bercabang banyak dan melebar seolah membentuk payung. Bentuk daun majemuk dan rapat, menciptakan kerimbunan yang khas dan memberikan kerindangan, serta kenyamanan bagi siapa pun yang berteduh di bawahnya. Pohon biola cantik memiliki kanopi yang cukup lebar dan daunnya tebal yang dapat menepis radiasi matahari. Pohon gempol mampu mencegah erosi dan menyediakan naungan. Pohon ini merupakan jenis pohon yang tangguh untuk reklamasi lahan kering. Pohon Tanjung merupakan jenis pohon yang berbunga dan bertajuk rindang. Bentuk tajuk bundar, daun-daunya lebat, tersusun beraturan membuat pohon ini dapat memberikan efek teduh.

Karakteristik jenis pohon pada kelas tajuk sedang secara keseluruhan merupakan pohon peneduh dan pohon yang memiliki estetika tinggi. Pohon tersebut cocok ditanam pada kelas tajuk sedang karena banyak pengunjung yang beraktivitas di kelas tajuk ini. Kerapatan pohon di kelas tajuk sedang lebih rendah dibandingkan dengan di kelas tajuk rapat. Hal ini dikarenakan jumlah jenis pohon yang rendah. Selain itu lokasi ini merupakan tempat bermain anak-anak sehingga sebagian besar area ini diperuntukkan untuk fasilitas bermain. Pemilihan jenis pohon yang tepat sangat diperlukan pada kelas tajuk sedang, hal ini dikarenakan banyaknya pengunjung yang beraktivitas di kelas tajuk ini. Vegetasi dapat meningkatkan fungsi estetika, sehingga semakin tinggi keanekaragaman jenis pohon, maka strata pohon yang terbentuk akan semakin beragam dan dapat memberikan keindahan lansekap pada hutan kota.

\section{Kelas Tajuk Jarang}

Kelas tajuk jarang merupakan lokasi perlintasan sepatu roda. Selain dijadikan lokasi perlintasan sepatu roda, kelas tajuk ini juga dijadikan fasilitas olahraga pengunjung, seperti jogging track.Kelas tajuk ini didominasi oleh ilalang tanpa ada pohon didalamnya. Tidak adanya pohon pada kelas tajuk ini menyebabkan suhu udara dilokasi ini lebih tinggi karena radiasi matahari langsung kepermukaan tanpa dihalangi oleh tajuk pohon (Prasetyo, 2012).

Kerapatan pohon pada hutan kota erat kaitannya dengan tutupan tajuk didalamnya. Tutupan tajuk hutan kota yang semakin rapat diduga mampu menurunkan suhu udara di dalam hutan kota serta menjadikan suasana di dalam hutan kota menjadi lebih nyaman. Keberadaan tajuk pohon akan memberikan keteduhan atau lingkungan mikro yang baik bagi keberadaan hutan kota (Setyowati, 2008).

\section{Suhu Udara dan Kelembaban Udara}

Hasil penelitian menununjukkan bahwa suhu udara dan kelembaban udara pada setiap kelas tajuk di Hutan Kota Patriot Bina Bangsa (tajuk rapat, tajuk sedang, tajuk jarang, dan luar hutan kota) sangat berbeda nyata. Data rata-rata temperatur udara (T) dan kelembaban udara $(\mathrm{RH})$ selama periode pengukuran di setiap titik pada pagi, siang, dan sore di Hutan Kota Patriot Bina Bangsa disajikan pada Gambar 2. 


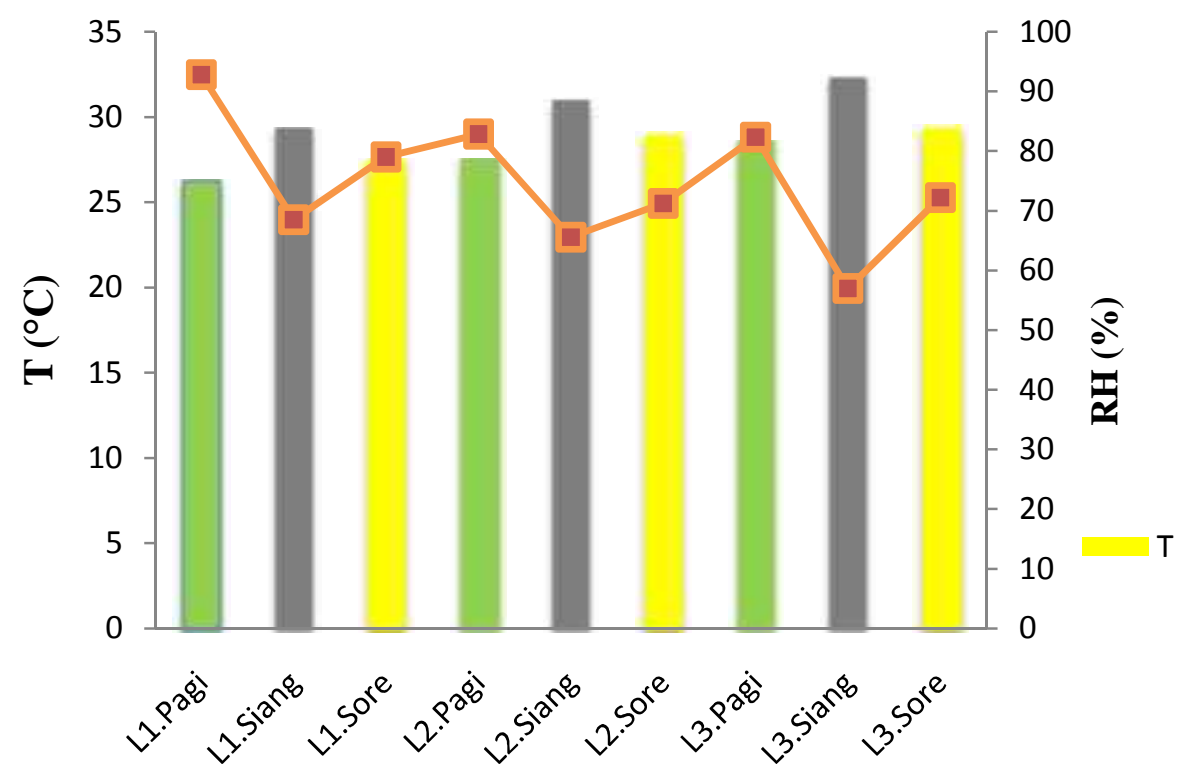

Gambar 2. Hubungan suhu udara dengan kelembaban udara.

\section{A. Suhu Udara}

Suhu udara merupakan salah satu unsur iklim yang memengaruhi kenyamanan hutan kota. Rata-rata suhu udara diketiga kelas tajuk Hutan Kota Patriot Bina Bangsa berbeda. Berdasarkan gambar diatas diketahui bahwa kelas tajuk rapat memiliki suhu udara lebih kecil dibandingkan dengan kelas tajuk lainnya. Hal ini disebabkan kelas tajuk rapat memiliki kerapatan jenis pohon yang lebih tinggi dibandingkan dengan kelas tajuk lainnya. Tajuk pohon yang saling bersinggungan menyebabkan radiasi matahari tidak langsung mampu menembus permukaan. Selain itu tajuk pohon dapat menyebarkan sinar matahari sehingga suhu area disekitarnya dapat direduksi (Sari, 2013). Hubungan suhu udara dan kerapatan disajikan pada Gambar 3.

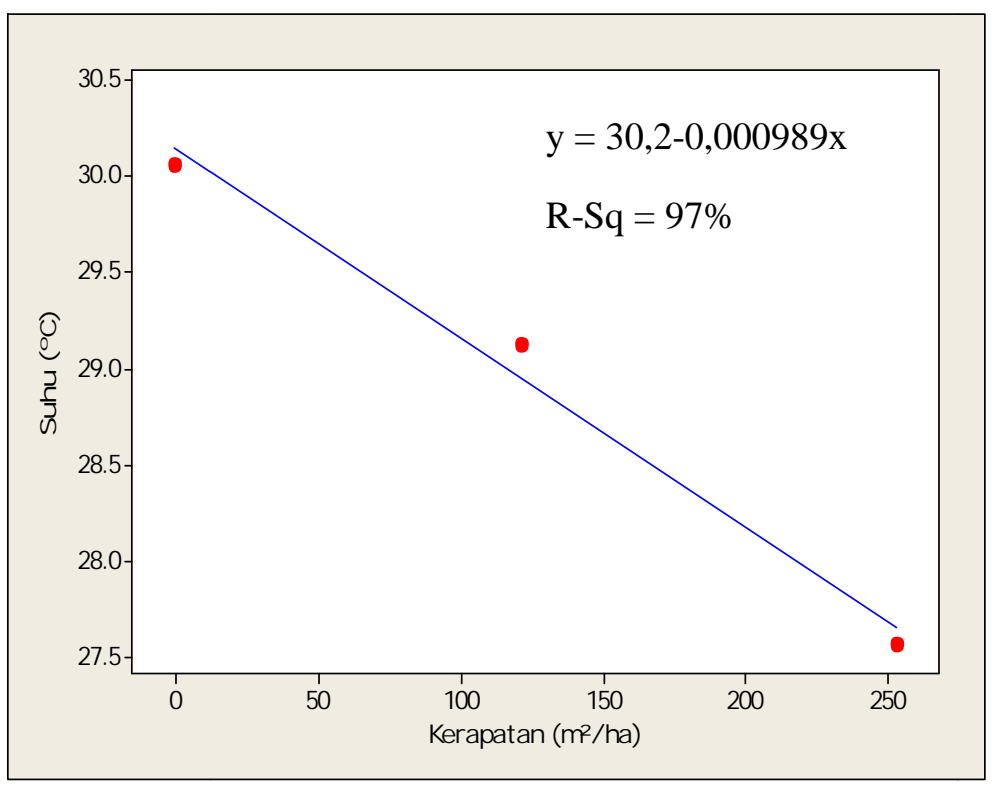

Gambar 3. Hubungan suhu udara dengan kerapatan pohon. 
Berdasarkan grafik diatas diketahui bahwa kerapatan pohon berpengaruh nyata terhadap suhu sebesar 0,077. Hasil analisis regresi menyatakan bahwa setiap ke-naikan kerapatan pohon sebesar 1 pohon/ha, maka akan menurunkan suhu udara sebesar $0,000989^{\circ} \mathrm{C}$. Model ini memiliki selang kepercayaan sebesar 97,1\%. Hasil penelitian menunjukkan bahwa semakin rapatnya pohon maka suhu udara di bawah tegakan akan semakin kecil.

Lakitan (1994), menyatakan bahwa semakin rapat tajuk pohon maka suhu udara ratarata dibawah tegakan akan semakin rendah dan kelembabanya akan semakin tinggi. Udara dibawah tegakan tersebut akan terasa lebih teduh dan sejuk. Lebih teduh karena intensitas cahaya matahari langsung sebagian besar tidak dapat menembus kanopi pohon tersebut. Lebih sejuk karena berkurangnya masukan energi cahaya matahari untuk memanaskan di bawah permukaan kanopi.

Lahan yang tersedia pada kelas tajuk sedang dikhususkan untuk taman bermain anak dan tempat berkumpulnya pengunjung. Tersedianya fasilitas bermain anak membuat lahan tanam untuk vegetasi semakin sempit. Hal ini menyebabkan kera-patan pohon pada kelas tajuk sedang lebih rendah dibandingkan dengan kelastajuk rapat. Kerapatan pohon yang rendah membuat sinar matahari langsung menembus permukaan. Hal ini menyebabkan suhu udara dipermukaan relatif lebih tinggi (Prasetyo, 2012).

Suhu udara di kelas tajuk jarang tertinggi dibandingkan dengan lokasi lain. Hal ini disebabkan di kelas tajuk ini penutup lahannya hanya berupa rumput, dan tidak adanya vegetasi pohon yang dapat mereduksi radiasi matahari. Radiasi matahari yang diterima langsung menyebabkan peningkatan suhu udara. Lakitan (1994), menyatakan suhu udara dibawah naungan karena radiasi matahari yang diterima tanaman tidak dapat dipantulkan kembali. Hakim dan Utomo (2013), menyatakan vegetasi pohon mampu mereduksi panas dari pancaran sinar matahari sehingga mampu menurunkan suhu udara.

Tingginya suhu udara pada kelas tajuk yang tidak ternaungi dikarenakan tidak adanya vegetasi berupa pohon. Vegetasi pohon pada hutan kota dapat menyerap panas melalui mekanisme penyerapan cahaya matahari yang sebagian dimanfaatkan dalam proses fotosintesis, sehingga radiasi panas matahari tidak memanaskan suhu udara di sekitar vegetasi tersebut yang berdampak pada efek pendinginan (Setiawan, 2014). Selain itu pada kelas tajuk jarang terdapat jalan yang terbuat dari paving block. Seperti yang dinyatakan oleh Dahlan (2011), bahwa jalan, aspal, paving, tembok dan atap gedung merupakan sebagian contoh dari permu-kaan kota yang berpotensi menaikkan suhu udara melalui refleksi, transmisi, dan absorbsi radiasi matahari.

\section{B. Kelembaban Udara}

Kelembaban udara merupakan salah satu unsur iklim mikro yang memengaruhi kenyamanan hutan kota. Rata-rata kelembaban udara di ketiga kelas tajuk Hutan Kota Patriot Bina Bangsa berbeda. Berdasarkan Gambar 2 diketahui bahwa kelas tajuk rapat memiliki kelembaban udara yang lebih tinggi di bandingkan dengan kelas tajuk lainnya. Tingginya kelembaban udara pada kelas tajuk rapat dipenga-ruhi oleh vegetasi penyusunnya. Vegetasi pohon memiliki kemampuan mengha-silkan uap air melalui proses evapotranspirasi (Edi, 2013).

Kelas Tajuk rapat merupakan tegakan mahoni yang memiliki kerapatan yang lebih tinggi dibandingkan dengan kelas tajuk lain. Hal ini menyebabkan uap air yang dihasilkan dari evapotranspirasi oleh vegetasi pohon lebih besar. Luas tutupan tajuk di kelas tajuk rapat lebih besar dibandingkan dengan kelas tajuk lainnya. Hal ini berarti kelas tajuk rapat dapat mereduksi radiasi matahari lebih baik diban-dingkan dengan kelas tajuk lainnya. Hasil peningkatan $\mathrm{H} 2 \mathrm{O}$ karena evapotrans-pirasi ini yang memengaruhi peningkatan kelembaban 
udara (Tauhid, 2009). Hubungan kelembaban udara dengan kerapatan disajikan pada Gambar 4.

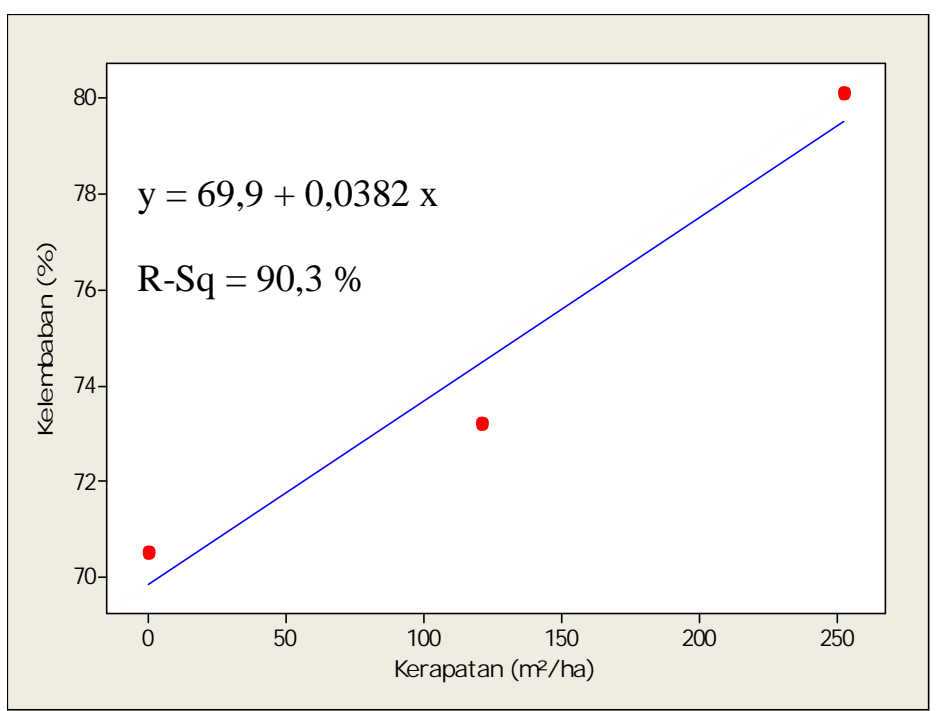

Gambar 4. Hubungan kelembaban udara dengan kerapatan pohon.

Berdasarkan grafik diatas diketahui bahwa kerapatan tidak berpengaruh nyata terhadap kelembaban udara sebesar 0,142 (\%). Hasil analisis regresi menyatakan bahwa setiap kenaikan kerapatan sebesar 1 pohon/ha maka akan menaikkan kelembaban udara sebesar 0,0382\%. Model ini memiliki selang kepercayaan sebesar 90,3\%. Hasil penelitian menunjukkan bahwa semakin rapatnya pohon maka kelembaban udara di bawah tegakan akan semakin tinggi.

Kelembaban udara pada kelas tajuk sedang lebih rendah dibandingkan dengan kelas tajuk rapat. Kerapatan pohon dan tutupan tajuk yang rendah menyebabkan tidak tertahannya laju sinar matahari oleh dedaunan sebelum mencapai permu-kaan tanah, sehingga suhu udara juga menjadi tinggi. Apabila sinar matahari tidak tertahan oleh dedaunan, maka terjadi peningkatan intensitas radiasi matahari akibat penyerapan dan pemantulan oleh gas, uap air dan partikel-partikel yang tersuspensi diudara. Kaka (2013), menyatakkan bahwa rendahnya kelembaban udara disebabkan oleh proses evapotranspirasi oleh air dan tanaman yang sangat kecil sehingga massa udara didaerah tersebut lebih sedikit mengandung uap air.

Kelas tajuk jarang merupakan lapangan terbuka sehingga uap air yang dihasilkan dari evapotranspirasi oleh vegetasi rumput lebih kecil dibandingkan dengan vegetasipohon. Pohon memiliki nilai kelembaban udara paling tinggi dibandingkan dengan semak dan rumput. Hal ini disebabkan oleh pohon memiliki kemampuan menghasilkan uap air dari proses transpirasi yang lebih besar dari pada semak dan rumput, sehingga kelembaban udaranya lebih tinggi. Rendahnya kelembaban udara di kelas tajuk jarang selain dipengaruhi oleh kondisi vegetasi tetapi dipengaruhi oleh angin. Lakitan (1994), menyatakan rendahnya kelembaban udara dipengaruhi oleh angin.

\section{Indeks Kenyamanan}

Kenyamanan lingkungan di Hutan Kota Patriot Bina Bangsa berdasarkan tiga kelas tajuk tergolong tidak nyaman. Nilai THI tersebut diperoleh dari nilai suhu udara rata-rata dan kelembaban udara rata-rata di lokasi pengukuran. Data tingkat kenyamanan Hutan Kota Patriot Bina Bangsa disajikan pada Gambar 5. 


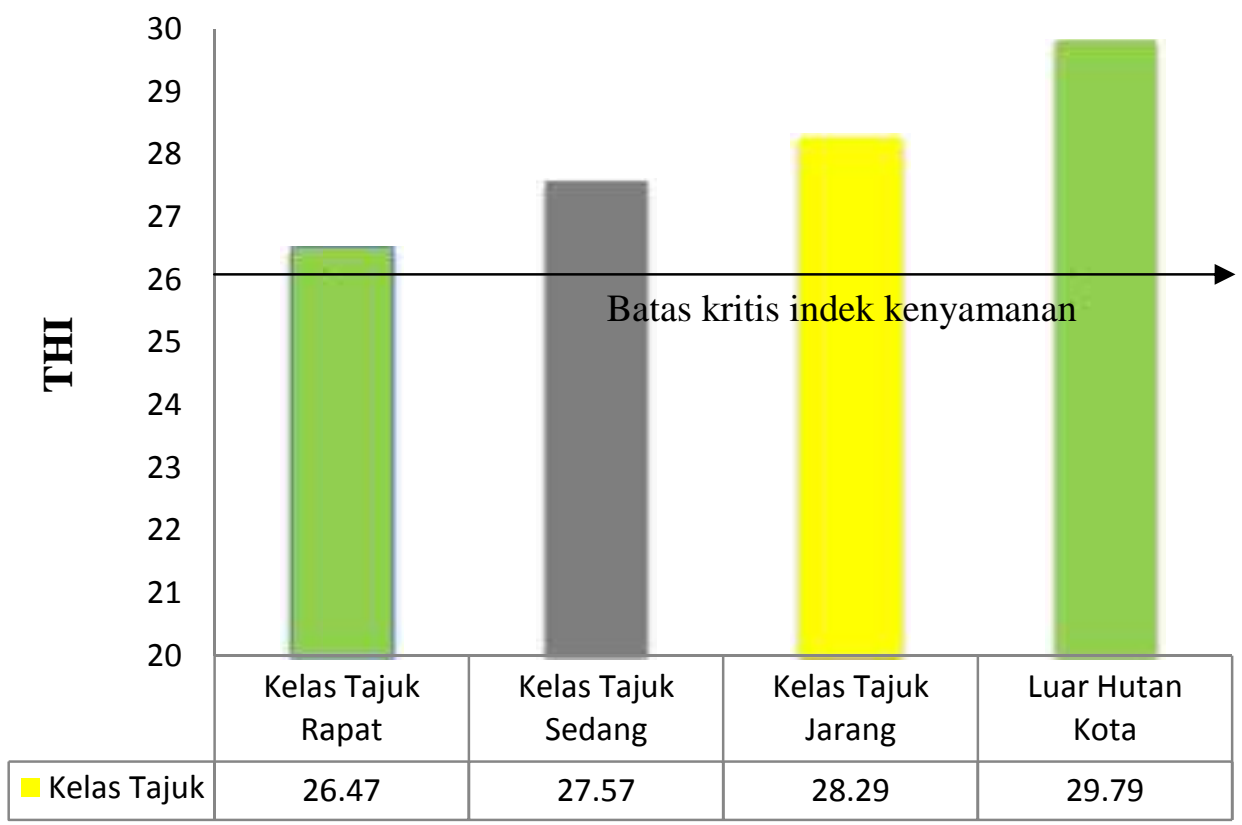

Gambar 5. Tingkat kenyamanan di Hutan Kota Patriot Bina Bangsa.

Berdasarkan kriteria THI Nieuwolt dan Mc Gregor (1990), suhu udara daerah tropis pada katagori tidak nyaman nilai THI > 26 dan suhu area dikatakan nyaman apabila nilai THI berada diselang 21-26. Oleh karena itu semua lokasi penguku-ran tergolong tidak nyaman. Kelas tajuk jarang temasuk paling tidak nyaman bila dibandingkan dengan kelas tajuk lain. Kelas tajuk ini memiliki suhu udara yang tertinggi hampir menyerupai suhu udara di luar Hutan Kota Patriot Bina Bangsa dan kelembaban terendah dibandingkan dengan lokasi lain, sehingga pada kelas tajuk ini paling tidak nyaman untuk beraktivitas. Hal ini dikarenakan lokasi ini bervegetasi rumput. Kondisi vegetasi ini tidak terdapat naungan, sehingga sinar matahari yang masuk tidak dapat disebarkan mengakibatkan penyerapan sinar tersebut cendrung lebih cepat sehingga suhu udara pada vegetasi rumput lebih panas dan tidak nyaman.

Gates (1970), menyatakkan bahwa suhu udara dan kelembaban udara merupakan parameter iklim yang memengaruhi kenyamanan manusia. Suhu udara yang terlalu tinggi atau terlalu rendah akan mengganggu aktivitas manusia. Kelas tajuk rapat memiliki nilai THI lebih rendah dibanding dengan kelas tajuk lainnya. Kerapatan dan luas tajuk yang lebih tinggi dibandingkan dengan kelas tajuk lain menyebabkan kemampuan evapotranspirasinya masih cenderung tinggi bila dibandingkan dengan lokasi lain.

Kondisi struktur vegetasi pohon dengan tajuk yang luas memengaruhi kondisi suhu udara dan kelembaban udara di dalamnya, sehingga nilai THI yang didapatkan disetiap kelas tajuk akan berbeda. Berdasarkan nilai THI diketahui bahwa semua katagori kelas tajuk di Hutan Kota Patriot Bina Bangsa tergolong tidak nyaman. Hal ini dikarenakan penutupan vegetasi penaung belum memiliki tutupan kanopi pohon yang cukup masif karena kondisi fisik tanaman yang masih muda dan belum mencapai ukuran optimal. Selain itu penutupan vegetasi yang kurang rimbun di ketiga kelas tajuk tersebut memberikan kesan tidak nyaman. Zahra dkk (2014), menyatakan karakter yang menonjol dari RTH dengan kualitas estetika tinggi dapat memberikan kesan teduh dan nyaman.Kondisi tersebut mengakibatkan radiasi matahari yang masuk cukup tinggi dan menyebabkan suhu udara disekitarnya menjadi tinggi. Besarnya nilai THI disetiap kategori kelas tajuk dipengaruhi kemampuan struktur hutan kota dalam mengontrol suhu dan kelembaban udara. 
Perbedaan kerapatan dan luas penutupan tajuk sangat menentukan iklim mikro pada hutan kota. Hal ini disebabkan oleh perbedaan karakteristik masing-masing jenis tutupan lahan dalam menyerap ataupun memantulkan energi matahari yang diterima. Menurut Hayati dkk (2013), kondisi vegetasi dengan kerapatan pohon yang tinggi akan memengaruhi kondisi iklim mikro (suhu udara dan kelembaban udara), kemudian akan menentukan tingkat kenyamanan berdasarkan nilai THI.

\section{Persepsi pengunjung terhadap fasilitas Hutan Kota Patriot Bina Bangsa}

Kegiatan rekreasi akan dilakukan seseorang bila tersedia fasilitas-fasilitas yang memadai atau memenuhi kegiatan mereka. Penilaian pengunjung tehadap Hutan Kota Patriot Bina Bangsa dibagi dalam 11 kriteria. Skor sangat baik dengan skor baik dijadikan satu yaitu baik, sedangkan skor buruk dengan sangat buruk dijadikan satu yaitu buruk. Berdasarkan hasil wawancara diketahui bahwa lebih dari 77,82 \% pengunjung menilai fasilitas di Hutan Kota Patriot Bina Bangsa tergolong baik, 22, $18 \%$ termasuk kategori buruk. Data persentase persepsi pengunjung terhadap Hutan Kota Patriot Bina Bangsa disajikan pada Tabel 5.

Tabel 5. Persepsi pengunjung terhadap Hutan Kota Patriot Bina Bangsa (\%).

\begin{tabular}{|c|c|c|c|c|c|}
\hline \multirow{2}{*}{ No } & \multirow{2}{*}{ Kriteria } & \multicolumn{4}{|c|}{ Skor } \\
\hline & & Sangat Baik & Baik & Buruk & Sangat Buruk \\
\hline 1. & Kondisi Jalan & 90 & 6 & 2 & 2 \\
\hline 2. & Aksebilitas & 100 & 0 & 0 & 0 \\
\hline 3. & Fasilitas Kebersihan & 43 & 45 & 10 & 2 \\
\hline 4. & Fasilitas Toilet & 24 & 24 & 52 & 0 \\
\hline 5. & Tempat Ibadah & 99 & 1 & 0 & 0 \\
\hline 6. & Taman Bermain & 9 & 15 & 75 & 1 \\
\hline 7. & Parkir Kendaraan & 32 & 47 & 18 & 3 \\
\hline 8. & Pelayanan Keamanan & 25 & 36 & 38 & 1 \\
\hline 9. & Keindahan Alam & 33 & 52 & 15 & 0 \\
\hline 10. & Kondisi Pohon & 58 & 29 & 7 & 6 \\
\hline & Kelembaban dan Suhu & 49 & 39 & 9 & 3 \\
\hline & Rata-rata & 51,09 & 26,73 & 20,55 & 1,64 \\
\hline
\end{tabular}

Sumber : Data primer (2015)

Berdasarkan hasil wawancara diketahui bahwa $90 \%$ pengunjung menilai kondisi jalan di kawasan Hutan Kota Patriot Bina Bangsa sangat baik. Hal ini dapat dili-hat dari kondisi jalan di Hutan Kota Patriot Bina Bangsa berupa koren blok. Untuk kriteria aksesibilitas pengunjung menilai bahwa aksesibilitas Hutan Kota Patriot Bina Bangsa baik (100\%). Hal ini dapat dilihat aksesibilitas menuju Hutan Kota Patriot Bina Bangsa sangat mudah, dapat ditempuh dengan kendaraan, baik kendaraan roda dua maupun roda empat. Lebih dari $80 \%$ pengunjung menilai bahwa kebersihan di dalam hutan kota tergolong baik. Hal ini dapat dilihat dengan adanya banyak tempat sampah di dalam kawasan dan terdapat petugas kebersihan sehingga membuat Hutan Kota Patriot Bina Bangsa terlihat bersih.

Penilaian pengunjung terhadap fasilitas toilet/wc adalah buruk. Lebih dari 50\% responden mengatakan bahwa kurang tersedianya banyak toilet dan kurang bersihnya toilet yang berada di dalam kawasan Hutan Kota Patriot Bina Bangsa menyebabkan penilaian pengunjung buruk. Penilaian pengunjung terhadap taman bermain anak buruk (76\%). Hal ini dapat dilihat karena kurangnya fasilitas ber-main anak dan kondisi fasilitas bermain yang tidak layak digunakan. Sebanyak 79\%pengunjung menilai kondisi lahan parkir yang berada 
di Hutan Kota Patriot Bina Bangsa baik. Hal ini dikarenakan tersedianya lahan parkir yang strategis, luas dan aman. Penilaian pengunjung terhadap keadaan keamanan dan pelayanan petugas informasi baik. Sebanyak $61 \%$ pengunjung menilai terdapatnya pos penjagaan dan papan informasi membuat pengunjung merasa keamanan di Hutan Kota Patriot Bina Bangsa baik. Penilaian terhadap keindahan di kawasan Hutan Kota Patriot Bina Bangsa adalah baik. Lebih dari $80 \%$ pengunjung menilai bahwa terdapatnya kolam pancuran dan banyaknya pohon membuat pengunjung merasa nyaman.

Penilaian pengunjung terhadap kondisi pohon di dalam kawasan Hutan Kota Patriot Bina Bangsa baik. Pengunjung menilai bahwa terdapatnya banyak jenis pohon dan rimbun membuat pengunjung merasa nyaman berada di dalam hutan kota. Penilaian pengunjung terhadap kelembaban dan suhu di Hutan Kota Patriot Bina Bangsa adalah sangat baik. Pengunjung merasakan udara yang sejuk, banyak angin dan tidak panas sehingga membuat pengunjung merasa nyaman berada di dalam hutan kota.

Berdasarkan hasil wawancara mengenai THI, 79 orang pengunjung menyatakan nyaman dan 21 orang menyatakan tidak nyaman. Penilaian ini berbeda dengan perhitungan THI berdasarkan suhu dan kelembaban di Hutan Kota. Perbedaan tersebut dikarenakan sebagian besar pengunjung merasa suhu udara didalam hutan kota relatif lebih rendah dibanding diluar hutan kota dan hutan kota menjadi alternatif lokasi rekreasi di wilayah perkotaaan.Hal ini yang membuat pengunjung merasa nyaman berada di dalam Hutan Kota. Selain itu vegetasi di dalam Hutan Kota memberikan kesan teduh dan nyaman. Zahra, dkk. (2014), mengatakan karakter yang menonjol dari hutan kota dengan kualitas estetika tinggi dapat memberikan kesan teduh dan nyaman. Banyaknya vegetasi di dalam hutan kota dibandingkan dengan di luar hutan kota membuat pengunjung merasa bahwa hutan kota dapat memberikan rasa nyaman bagi pengunjung.

\section{SIMPULAN DAN SARAN}

\section{Simpulan}

Berdasarakan tujuan dan hasil penelitian dapat diambil beberapa kesimpulan antara lain.

1. Ditemukan 15 jenis pohon penyusun Hutan Kota Patriot Bina Bangsa, dan pada kelas tajuk rapat memiliki kerapatan tertinggi dan luas tutupan tajuk terbesar yaitu 252,51 pohon/ha dan $16.915,14 \mathrm{~m}^{2} /$ ha.

2. Semakin tinggi kerapatan pohon maka temperatur udara akan semakin rendah dan kelembaban akan semakin tinggi.

3. Berdasarkan kriteria THI, nilai tingkat kenyamanan Hutan Kota Patriot Bina Bangsa disemua lokasi pengukuran tergolong tidak nyaman yaitu $>26$.

4. Persepsi pengunjung terhadap fasilitas di Hutan Kota Patriot Bina Bangsa tergolong baik $(77,82 \%)$.

\section{Saran}

1. Perlu peningkatkan jenis dan jumlah vegetasi pohon penyusun Hutan Kota Patriot Bina Bangsa agar lebih nyaman dan sejuk.

2. Perlu perbaikan fasilitas di Hutan Kota Patriot Bina Bangsa seperti toilet dan taman bermain agar kenyamanannya akan semakin meningkat. 


\section{DAFTAR PUSTAKA}

Ahmad, F., Arifin, H.,Dahlan, E., Effendy, S., dan Kurniawan, R. 2012. Analisis hubungan luas ruang terbuka hijau (rth) dan perubahan suhu di Kota Palu. Jurnal Hutan Tropis. 13(2): 173-180.

Arikunto, S. 2011. Prosedur Penelitian Suatu Pendekatan Praktik. Buku. Rineka Cipta. Jakarta. $256 \mathrm{p}$.

Dahlan. 2011. Potensi hutan kota sebagai alternatif substitusi fungsi alat pendingin ruangan (air conditioner). Skripsi. IPB. Bogor. 65 p.

Edi, S. 2013. Pengaruh struktur vegetasi terhadap iklim mikro kawasan Kota Tanggerang. Skripsi. IPB. Bogor. 69 p.

Fandeli, C.H. 1992. Analisis Mengenai Dampak Lingkungan Prinsip Dasar dan Pemanfaatannya Dalam Pembangunan. Buku. Liberty. Yogyakarta. 176 p.

Gates, D. M. 1972. Man and His Enviroment : Climate. Buku. Harper and Row. New York. $175 p$.

Hakim, R., dan Utomo, H. 2003. Komponen Perancangan Arsitektur Lansekap: Prinsip, Unsur dan Aplikasi Desain. Buku. Bumi Aksara. Jakarta. 287 p.

Hayati, J.,Santun, R.P., dan Siti, N. 2013. Pengembangan ruang terbuka hijau dengan pendekatan kota hijau di Kota Kandangan.Jurnal Tata Lokas. 14 (4) : 306-316.

Hussein, R., Bagyo, Y., dan Soemarno. 2010. Analisis kualitas dan kenyamanan lingkungan kawasan hutan kota di Kota Malang. Jurnal Agritek 18(2):245-267.

Kaka,M. A. 2013. Perencanaan ruang terbuka hijau untuk ameliorasi iklim mikro Kota Depok. Skripsi. IPB. Bogor. 80 p.

Lakitan, B. 1994. Dasar-Dasar Klimatologi. Buku. Raja Grafindo Persada. Jakarta 173 p.

Laksmiwati, T., Chairil, B.A., Wulan. A. 2013. Evaluasi ruang terbuka di Kampus Universitas Brawijaya. Jurnal RUAS. 11 (1): 334-347.

Nieuwolt,S., McGregor G. R. 1998. Tropical Climatology. Buku. England (UK) :JohnWiley $\&$ Sons Ltd. 352p.

Prasetyo, A.T. 2012. Pengaruh ruang terbuka hijau (rth) terhadap iklim mikro di Kota Pasuruan. Skripsi. IPB. Bogor. 58 p.

Rahmawati, S.N. 2014. Kemampuan hutan kota dalam ameliorasi iklim mikro di Kampus IPB Darmaga. Skripsi. IPB. Bogor. 32 p.

Sari, N. A. 2013. Evaluasi hutan kota berdasarkan fungsi ameliorasi iklim mikro di Kota Semarang. Skripsi. IPB. Bogor. 40p.

Setyowati, D.L.2008. Iklim Mikro Dan Kebutuhan Ruang Terbuka Hijau Di Kota Semarang. Jurnal Manusia dan Lingkungan. 15(3) : 125-140.

Tauhid. 2008. Kajian jarak jangkau efek vegetasi pohon terhadap suhu udara pada siang hari di perkotaan. Tesis. Universitas Diponogoro. Semarang. 126 p.

Tjasyono, B. 1992. Klimatologi Umum. Buku. ITB Press. Bandung. 210 p.

Zahra, A., Sitawati, F., Agus, S. 2014. Evaluasi Keindahan dan Kenyamanan Ruang Terbuka Hijau (Rth) Alun-Alun Kota Baru. Jurnal produksi tanaman. 2. (7): 514-532.

Zoer`aeni. 1995. Hutan kota dan lingkungan kota. Makalah Seminar pada Fakultas Arsitektur Lansekap dan Teknik Lingkungan Universitas Trisakti. Jakarta. 25 p. 